\title{
Estudo do benefício e da aclimatização em novos usuários de próteses auditivas****
}

\author{
Study of benefit and of acclimatization in recent users of hearing aids
}

Raquel Martins da Costa Amorim*
Katia de Almeida**

*Fonoaudióloga. Mestre em

Fonoaudiologia pela Universidade

Veiga de Almeida. Professora Titular do

Curso de Fonoaudiologia da Fead -

Minas. Endereço para correspondência:

Rua São Domingos do Prata, 510 / 602

- Belo Horizonte - MG - CEP 30330-

110 (raquel.amorim@fead.br).

**Fonoaudióloga. Doutora em Distúrbios da Comunicação Humana. Professora Adjunto da Faculdade Ciências Médicas da Santa Casa de Misericórdia de São Paulo.

****Trabalho Realizado na Universidade Veiga de Almeida Rio de Janeiro.

Artigo de Pesquisa

Artigo Submetido a Avaliação por Pares

Conflito de Interesse: não

Recebido em 17.03.2006.

Revisado em 05.06.2006, 20.11.2006; 23.02.2007.

Aceito para Publicação em 23.02.2007.

\begin{abstract}
Background: benefit and acclimatization. Aim: to characterize the short-term benefits presented by adults, recent users of hearing aids, through objective (functional gain) and subjective (self-evaluation questionnaires) procedures. The possible occurrence of the phenomenon of acclimatization was also investigated based on the analysis of the speech recognition percent index (SRPI) before the fitting of the hearing aids and after four and 16/18 weeks of hearing aids use. Method: sixteen subjects, with ages between 17 and 89 years, with symmetric moderate or severe sensorineural hearing loss, recent hearing aid users, were evaluated. The study was divided in three phases: before the hearing aids fitting, and after four and 16/18 weeks following the fitting process. In all of the phases the following procedures were used: pure tone audiometry, speech recognition percent index, speech recognition threshold and the Hearing Handicap Inventory for Elderly Screening Version or the Hearing Handicap Inventory for the Adults Screening Version, and the Abbreviated Profile of Hearing Aid Benefit. After the hearing aid fitting process, subjects were submitted to free field audiometry. Results: results showed statistically significant differences between objective and subjective measures after the use of hearing aids, indicating short-term benefit. However, as time went by, the benefit obtained with the use of hearing aids did not improve significantly, suggesting that benefit does not increase with time. SRPI as well as subjective measures improved with long-term hearing aid use, but such differences were not statistically significant. Conclusions: short-term benefits were obtained with the use of hearing aids, however the phenomenon of acclimatization was not observed through the SRPI.
\end{abstract}

Key Words: Hearing Aids; Neuronal Plasticity and Hearing Loss.

\section{Resumo}

Tema: benefício e aclimatização. Objetivos: caracterizar o benefício de curto prazo em adultos novos usuários de próteses auditivas, por meio de procedimentos objetivos (ganho funcional) e subjetivos (questionários de auto avaliação) e estudar o fenômeno de aclimatização, a partir da análise dos índices percentuais de reconhecimento de fala (IPRF) dessa população antes da adaptação e após quatro e 16/18 semanas de uso da amplificação. Métodos: participaram deste estudo 16 indivíduos portadores de perda auditiva bilateral simétrica neurossensorial ou mista de grau moderado a severo, novos usuários de próteses auditivas, na faixa etária entre 17 a 89 anos. Nos três momentos da pesquisa: antes da adaptação das próteses auditivas, após quatro semanas e 16/18 semanas, foi realizada audiometria tonal liminar, o IPRF, o limiar de reconhecimento de fala e a aplicação dos questionários: Hearing Handicap inventory for Elderly Screening Version ou Hearing Handicap Inventory for the Adults Screening Version e Abbreviated Profile of Hearing Aid Benefit. Após a adaptação, foi realizado o ganho funcional. Resultados: revelaram diferenças estatisticamente significantes nas medidas objetivas e subjetivas após o uso das próteses auditivas, indicando benefício de curto prazo. Contudo, ao longo do tempo de uso da amplificação não ocorreu uma melhora significante do benefício, sugerindo que este não aumenta com o tempo. Foi observada melhora da média dos IPRF e das medidas subjetivas do benefício auditivo ao longo do tempo de uso da amplificação, contudo estas diferenças não foram estatisticamente significantes. Conclusão: ocorreu benefício a curto prazo com o uso das próteses auditivas, contudo não foi possível verificar a ocorrência do fenômeno da aclimatização por meio do IPRF.

Palavras-Chave: Auxiliares de Audição; Plasticidade Neuronal; Perda Auditiva

Referenciar este material como:

$\Omega$ AMORIM, R. M. C.; ALMEIDA, K. Study of benefit and of acclimatization in recent users of hearing aids (original title: Estudo do benefício e da aclimatização em $\sum 3$ novos usuários de próteses auditivas). Pró-Fono Revista de Atualização Científica, Barueri (SP), v. 19, n. 1, p.39-48, jan.-abril 2007. 


\section{Introduction}

The acquired hearing impairment in the adult age immensely harms the quality of life and the integration in the society. Due to the hearing loss, many individuals modify their life habits, consequently affecting their emotion, professional career, and social relationship. When there is not a surgical treatment or medicine therapy to solve the hearing impairment, the otolaryngologist indicates the use of hearing aids as an alternative to minimize the damages caused by hearing loss.

However, in the clinical practice is observed a significant latency time between the indication of sound amplification usage and the effectiveness of hearing aids adaptation. In addition to the hearing loss and devoid of hearing aids usage, the hearing impaired can develop eventually a decrease in the speech discrimination testing scores due to sensorineural deprivation. The gradual deterioration in the auditory performance is related to the reduction of acoustic information availability, although it is not perceived in an aided ear (Silman et al., 1984).

According to Willot (1996), the cochlear lesion implies a neural reorganization along the auditory pathway, known as plasticity. The neural plasticity refers to the ability of the central auditory system to reorganize subsequent to a peripheral injury and to modify its function in response to auditory stimulation. If neural plasticity is correlated to auditory injury, what happens when a hearing impaired wears hearing aids? The hearing aids launches an auditory stimulation from the sound amplification, this fact could entail a new occurrence of plasticity into the auditory system. This consideration instigates another important auditory effect: the use of the amplification can improve speech recognition over time.

The phenomenon related to auditory stimulation and that might improve the ability of speech recognition was called "acclimatization". The acclimatization effect is defined as a systematic enhancement of speech recognition over time, as soon as the hearing impaired learns new speech tracks available with the sound amplification usage (Arlinger et. al., 1996).

The interest in the acclimatization phenomenon has raised, hence, many questions emerge about the necessary length of time to expect afterward the hearing aid fitting process, or follow-up, before concluding that no other benefit could occur. However, how this benefit could be assessed?
Traditionally, the benefit obtained with the hearing aids usage has been evaluated via objective data, depending on the nature and severity of hearing loss, measured through the threshold and suprathreshold (Weinstein, 1997).

Considering the inconsistent relation between the objective measures and the subjective ones, the subjective measures of the benefit of hearing aid usage has conquered clinical acceptance and become a crucial component to be considered in the hearing aid fitting process (Weinstein, 1996).

Therefore, the main purpose of this current study were: to verify short-term benefits in first- time hearing aid wearers and to study the possible occurrence of acclimatization phenomenon through comparative analysis of word discrimination testing scores and subjective measures in the initial fitting process, past four and after 16/18 weeks of hearing aid use by all participants.

\section{Method}

The casuistic of this study was constituted by 16 hearing- impaired individuals of both gender (seven male and nine female), between 17 and 89 years old, mean age of 60,63 . All participants had symmetric moderate to severe bilateral mixed or sensorineural hearing loss (Davis and Silverman, 1970) and first-time hearing aid users were evaluated. The study participants consented to accomplish this research and the disclosure of its results with the agreement resolution 196/96. The procedures carried through and the selection of the study participants were described and had been approved by the Committee of Ethics in Research of the Universidade Veiga de Almeida(UVA), under the code number 08/04, date of December 21st of 2004.

The individuals were fitted with hearing aids from Siemens Manufacturer, digital technology with no linear amplification. There was not restriction about hearing aid model, therefore, the in- the-ear, hearing aid model, has been fitted in 14 participants and only two had used behind-the-ears. Among the participants, eight had opted to bilateral amplification and eight for the monaural amplification.

All subjects were referred by otolaryngologist as candidates of hearing aids. After obtaining patient history and signature of written consent, the external auditory canal was inspected. In the presence of occlusion by cerumen, the patients were sent to their primary care for wax removal. 
Subsequently, the pure-tone audiometry was performed, speech discrimination scores (DS), speech recognition testing (SRT), ear mold impression, and then inventories application of Hearing Handicap inventory for Elderly Screening Version (H.H.I.E.-S.) or Hearing Handicap Inventory for the Adults Screening Version (H.H.I.A.-S.), and Abbreviated Profile of Hearing Aid Benefit (A.P.H.A.B.) in the condition without hearing aids.

In a second moment, the hearing aid fitting process was carried out, next the adjustments in the computer, and instructions to the patient. In the first follow-up visit, the patient went through a free-field audiometry. Then, the functional gains of hearing aids were established. The functional gain of a hearing aid typically is determined by comparing aided and unaided free- field thresholds.

The testing was done at the following frequencies 2, 3, 4, 1, 0,5 and 0,25 KHz. After a month of use of hearing aid, the participants did another pure-tone audiometry to verify that their auditory ability had not modified.

After four and 16/18 weeks of use of amplification, it was performed another pure-tone audiometry, DS, SRT, and the amplification of the following questionnaires: H.H.I.E.-S. or H.H.I.A.S. and A.P.H.A.B. in the condition of wearing aids.

During hearing evaluation, the auditory thresholds were determined by air conduction in the frequencies of 0,25 to $8 . \mathrm{KHz}$, and by bone conduction in the frequencies range of 0,5 to $4 . \mathrm{KHz}$. The SRT was obtained by descend technique, trissyllable words, according to Russo et al (2005). The speech discrimination percentage scores were assessed through word lists recorded into a compact disk with 50 monosyllables, proposed by Pen e Mangabeira-Albernaz (1973), presented at a comfortable level of 25-40 dBNS above SRT threshold. This word list is composed by 25 monosyllable words phonetically balanced and presented at four different combinations. Each ear was assessed with 25 words, totalizing 50 words. All hearing tests were conducted in a sound-treated test booth and through the audiometer equipment model Siemens SD25 calibrated according to standard ISO 8253-1 (1989), in April 28th, 2004.

The characteristics of functional gain and frequencies responses of hearing aid users were prescribed by National Acoustics Laboratories e o Cooperative Research Center for Cochlear Implant, Speech and Hearing Research - N.A.L-NL1 (Dillon, 1999).
The inventory A.P.H.A.B. was applied to evaluate the amplification benefit at the initial period of hearing aids adaptation. This is the shortversion for Profile of Hearing Aid Benefit (P.H.A.B.), and both of them were elaborated by Cox and Alexander (1995). In Brazil, this inventory was adapted to Portuguese by Almeida, Gordo, Iorio e Scharlach (Almeida, 1998).

The APHAB is a 24-item self-assessment inventory in which patients report the amount of trouble they are having with communication or noises in various everyday situations. Benefit is calculated by comparing the patient's reported difficulty in the unaided condition with their amount of difficulty when using amplification. The APHAB produces scores for 4 subscales: Ease of Communication (EC), Reverberation (RV), Background Noise (BN), and Aversiveness (AV). Benefit index are calculated by a scoring software specific to A.P.H.A.B., in which are inserted patient answers that can be: always $(99 \%)$, very often $(87 \%)$, often (75\%), sometimes (50\%), rarely (25\%), very rarely $(12 \%)$ or never $(1 \%)$.

The handicap effects were evaluated by H.H.I.E.-S. Inventory, that is a short-version of Hearing Handicap Inventory for the Elderly (H.H.I.E.) elaborated by Ventry and Weinstein (1982). In 1990, the H.H.I.E. was modified to be administered to adults below 65 years old, known as Hearing Handicap Inventory for the Adults (H.H.I.A.). However, in this current study were used the short-version of both inventories: H.H.I.E.-S. and H.H.I.A.-S.

The HHIE-S is a self-administered, 10-item questionnaire designed to detect emotional and social problems associated with impaired hearing. Patients answer 5 questions, each concerning the emotional and social impact of their hearing loss on their lives, by responding yes (4 points), sometimes ( 2 points), or no (0 points); total HHIE$\mathrm{S}$ scores range from 0 to 40 . The short- version inventories were chosen due to its applicability.

According to Brazilian Elderly Status Guidelines (2003), elaborated by Brazilian Health Department, the concept of elderly people in Brazil is referred to individuals aged 60 years old or more. For that reason, in this study was administered the H.H.I.A.$S$ version to participants below 60 years old, and the H.H.I.E.-S version to participants above 60 years old. All the inventories questions were asked by the examiner, disregarding participants' age. 
The H.H.I.E.-S. was adapted to Portuguese by Wieselberg in 1997 and the other version H.H.I.A.S. was introduced and adapted by Almeida (1998). In these inventories, participants were instructed to answer "yes", "sometimes", and "no". Each answer respectively correspondent to four, two, or zero points. The score could vary among 0 to $40 \%$, with a highest score indicative of a better self- perception of handicap.

In this study, the questionnaires were applied in 3 different situations: before hearing aids fitting process, after 4 weeks and 16/18 weeks of hearing aids usage by all participants.

The acclimatization phenomenon was analyzed through the assessment of the benefit with hearing aids, the reevaluation of speech discrimination testing scores, and subjective measures over time to verify speech recognition improvement from hearing aid wearers. In order to assess the benefit with hearing aids, it was used objective measures via functional gain, and subjective ones via H.H.I.E.-S. or H.H.I.A-S (H.H.I.E./A.-S.) and A.P.H.A.B.

It was used the statistic test, $t$ test, to compare all the results obtained from objective and subjective measures among the 24 aided ears. It was used the statistic test, Wilcoxon Signed Ranks test, to compare, in the three study phases, the results of DS from aided and non-aided ears from the group of eight individuals who have chosen monaural amplification, and another comparative study to verify the results of DS from the group of eight individuals who have chosen binaural amplification.

\section{Results}

\section{Part 1}

Study of auditory benefit

Initially, in the Graph 1 are presented the mean values of auditory thresholds, with and without hearing aids. After comparing and analyzing these results, it was observed a significant statistical difference at all frequencies, $\mathrm{p}=0,00$.

The Graph 2 shows the results obtained from inventories H.H.I.A/E.-S. Comparing the phase before fitting process to the phases four weeks and $16 / 18$ weeks, the results obtained without hearing aids (phase before) were significantly higher than the other scales obtained after fitting process with hearing aids $(\mathrm{p}=0,00)$. However, when the results obtained from the inventories applied 4 and $16 / 18$ weeks were compared, the statistical analysis did not reveal significant statistical differences at all scales $(\mathrm{p}<0,05)$.

In order to finalize the subjective measures in this current study, the Graphs 3 e 4 presented the results obtained from the A.P.H.A.B. inventory. Comparing the phase before fitting process to the phases four weeks and 16/18 weeks, the results acquired without hearing aids (phase before) were significantly higher than the other scales obtained after fitting process with hearing aids $(p=0,00)$. However, when the results obtained of the benefit from the A.P.H.A.B. inventory applied in the phases 4 and 16/18 weeks were compared, the statistical analysis revealed significant statistical difference only at subscale Aversiveness (AV), $(\mathrm{p}=0,01)$.

\section{Part 2}

\section{Study of Acclimatization Phenomenon}

The ears analyzed in this phase were the ones, which received hearing aids, being a total of 24 ears. Next, the graphic 5 shows average percentage of speech discrimination scores obtained from each ear in the 3 phases of this study. Comparing the results obtained between the phases: before and after 4 weeks, and before and after 16/18 weeks, there was no significant statistical difference among speech discrimination scores $(\mathrm{p}<0,05)$

In this part of the study were related and compared the results of word discrimination scores obtained of 8 individuals that chose monaural amplification in which the non-aided ears were classified as the control group, and the aided ears as the experimental group.

In the graphic 6 shows average scores of word discrimination obtained in the aided ears and in the non-aided ears in the three phases of this study: before fitting process of hearing aids, after 4 weeks, and after 16/18 weeks. Comparing the three phases, there were not significant statistical difference among the SD scores from experimental group and control group $(\mathrm{p}<0,05)$.

The graphic 7 represents the mean values of SD from each ear (right and left) of 8 individuals who opted by binaural amplification. Comparing the results obtained between the phases: before and after 4 weeks, and before and after 16/18 weeks, there was no significant statistical difference among speech discrimination scores from each ear, $(\mathrm{p}<0$, 05). 


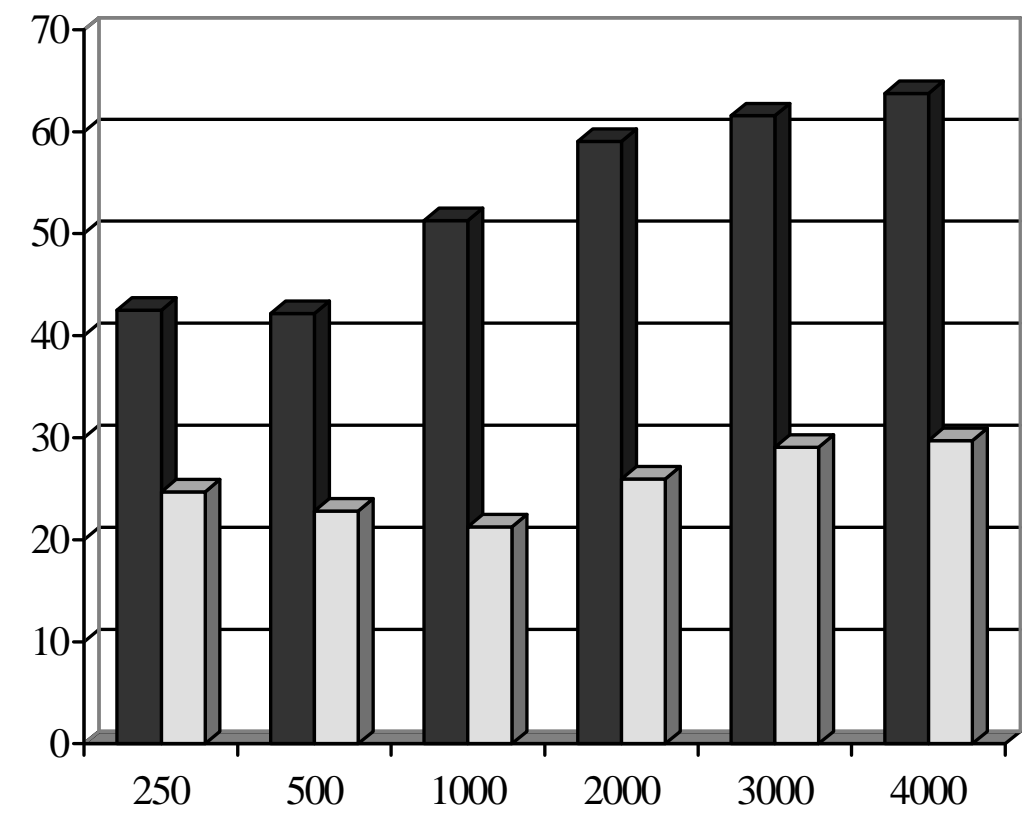

without hearing aids

$\square$ with hearing aids

GRAPH 2 - Percentage Value Means obtained from inventories H.H.I.E-S. or H.H.I.A.-S. (\%), in the phases before wearing hearing aids, after four weeks and 16/18 weeks of hearing aids usage.

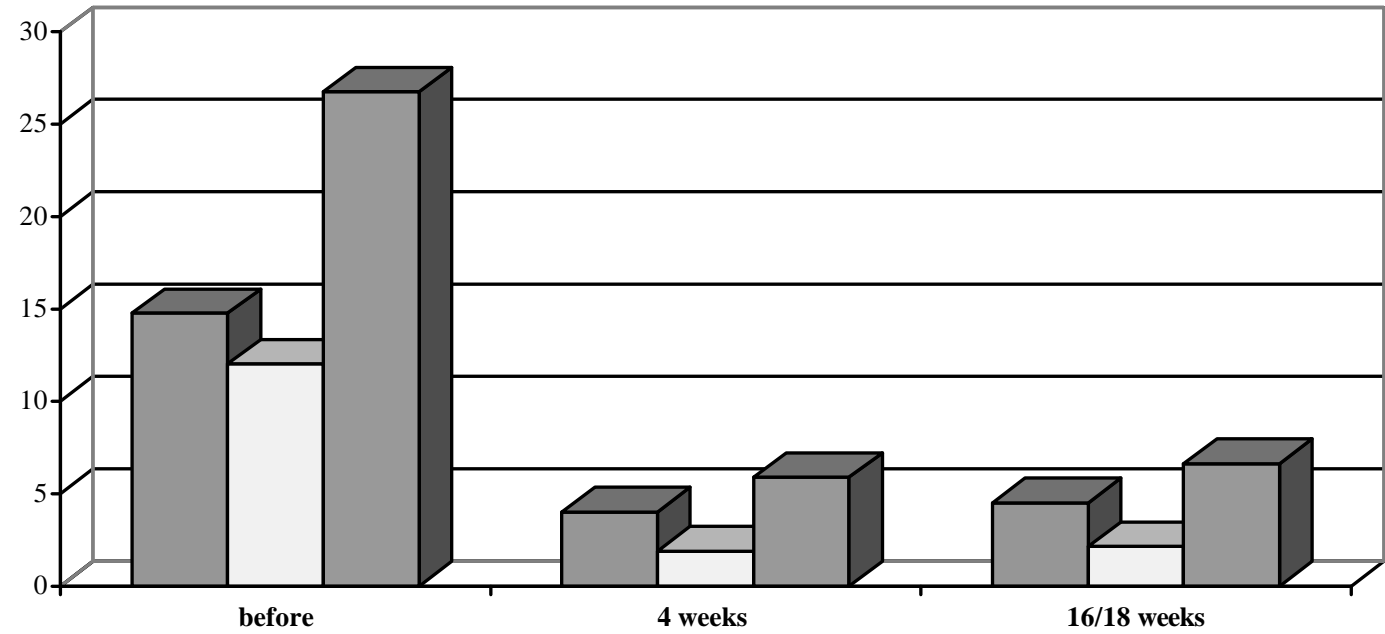


GRAPH 3 - Percentage Value Means obtained from inventories A.P.H.A.B.(\%), in the phases before wearing hearing aids, after four weeks and 16/18 weeks of hearing aids usage.

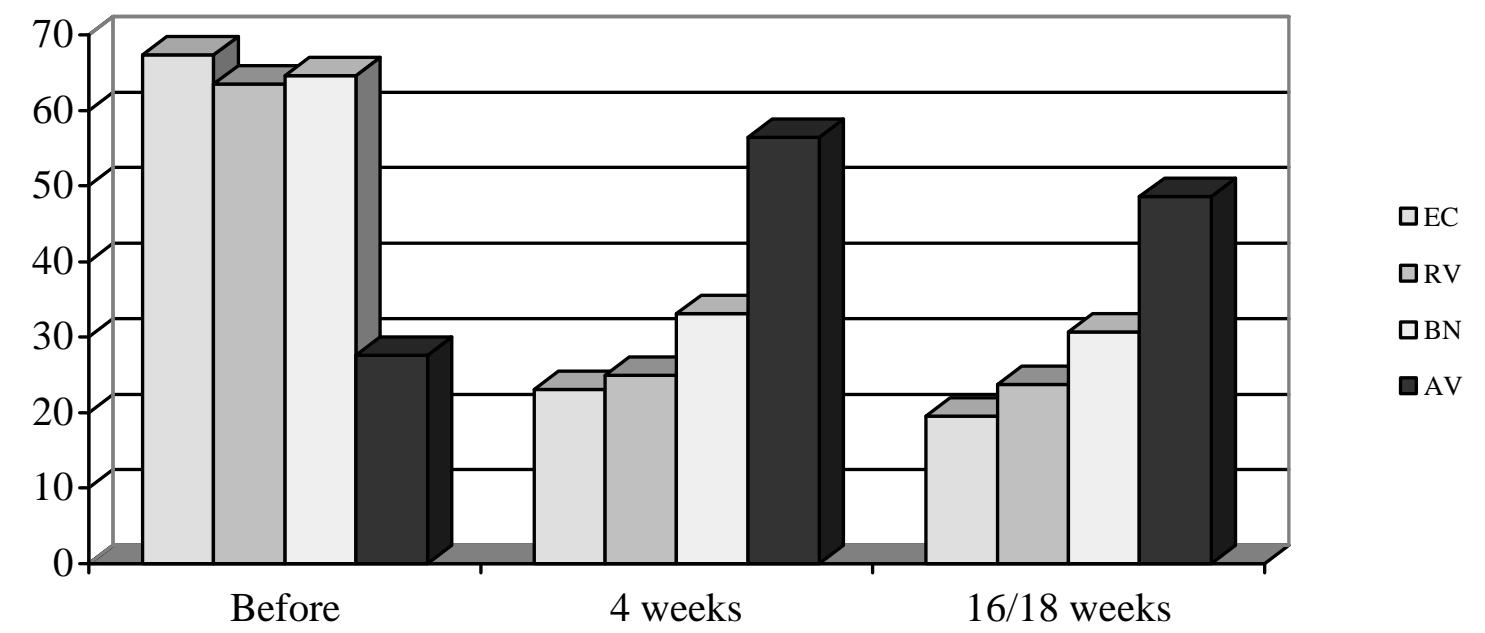

GRAPH 4 - Percentage Value Means of benefit obtained from inventories A.P.H.A.B. (\%), after four weeks and 16/18 weeks of hearing aids usage.

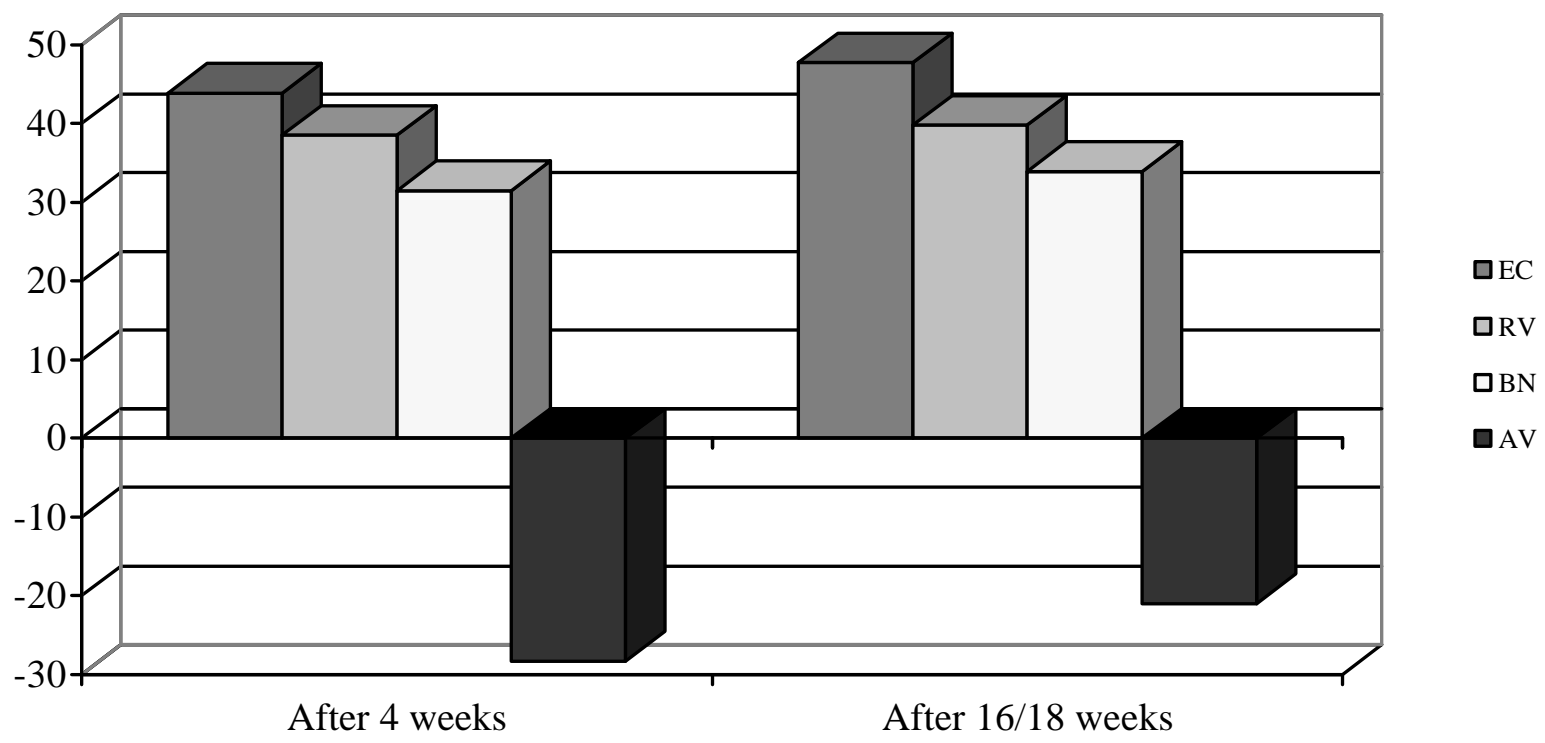


GRAPH 5 - Mean Values of Speech Discrimination Scores (\%).(\%), in the phases before wearing hearing aids, after four weeks and $16 / 18$ weeks of hearing aids usage.

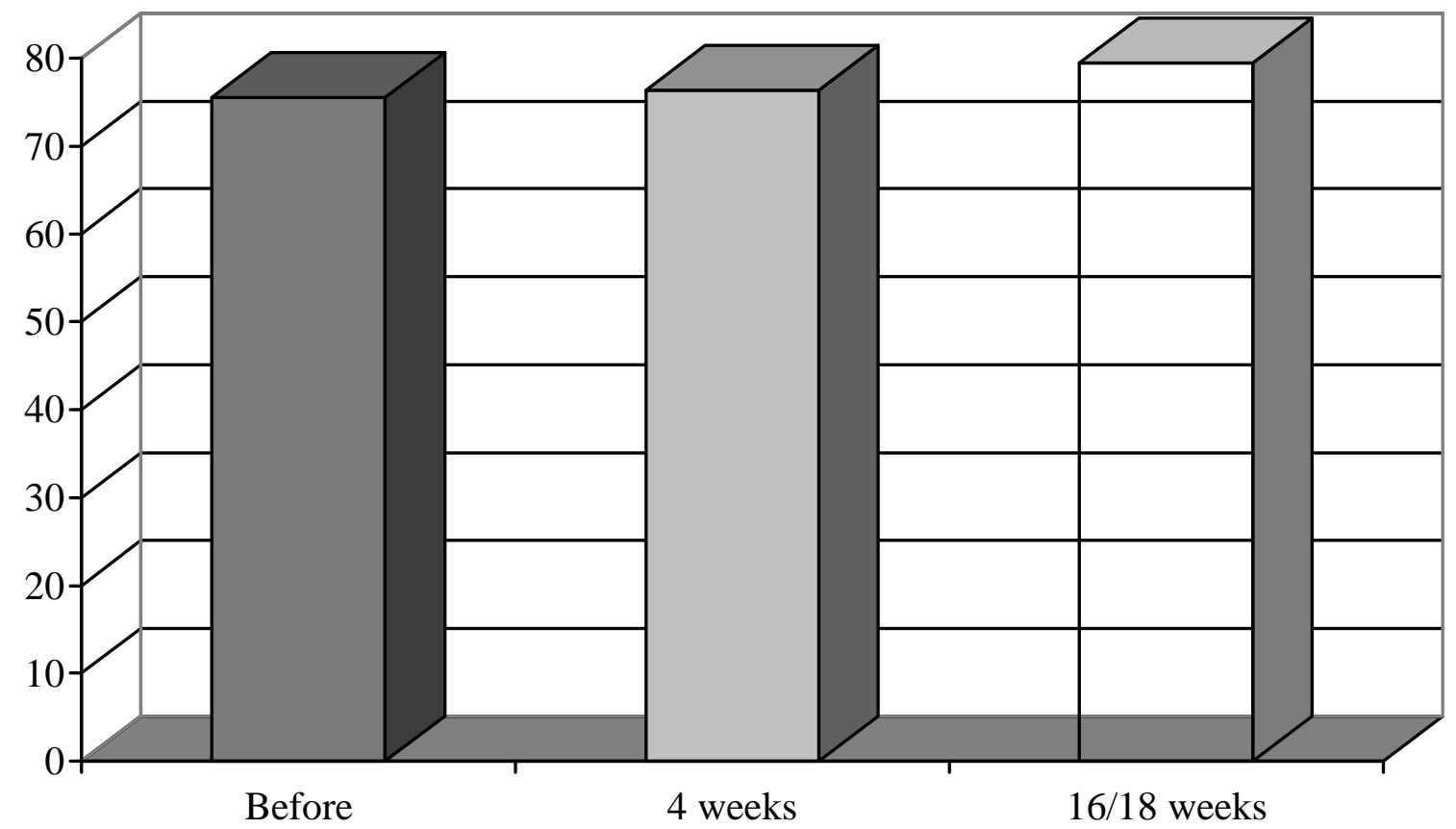

GRAPH 6 - Percentage Values Mean of Speech Discrimination scores from eight individuals with monaural amplification.

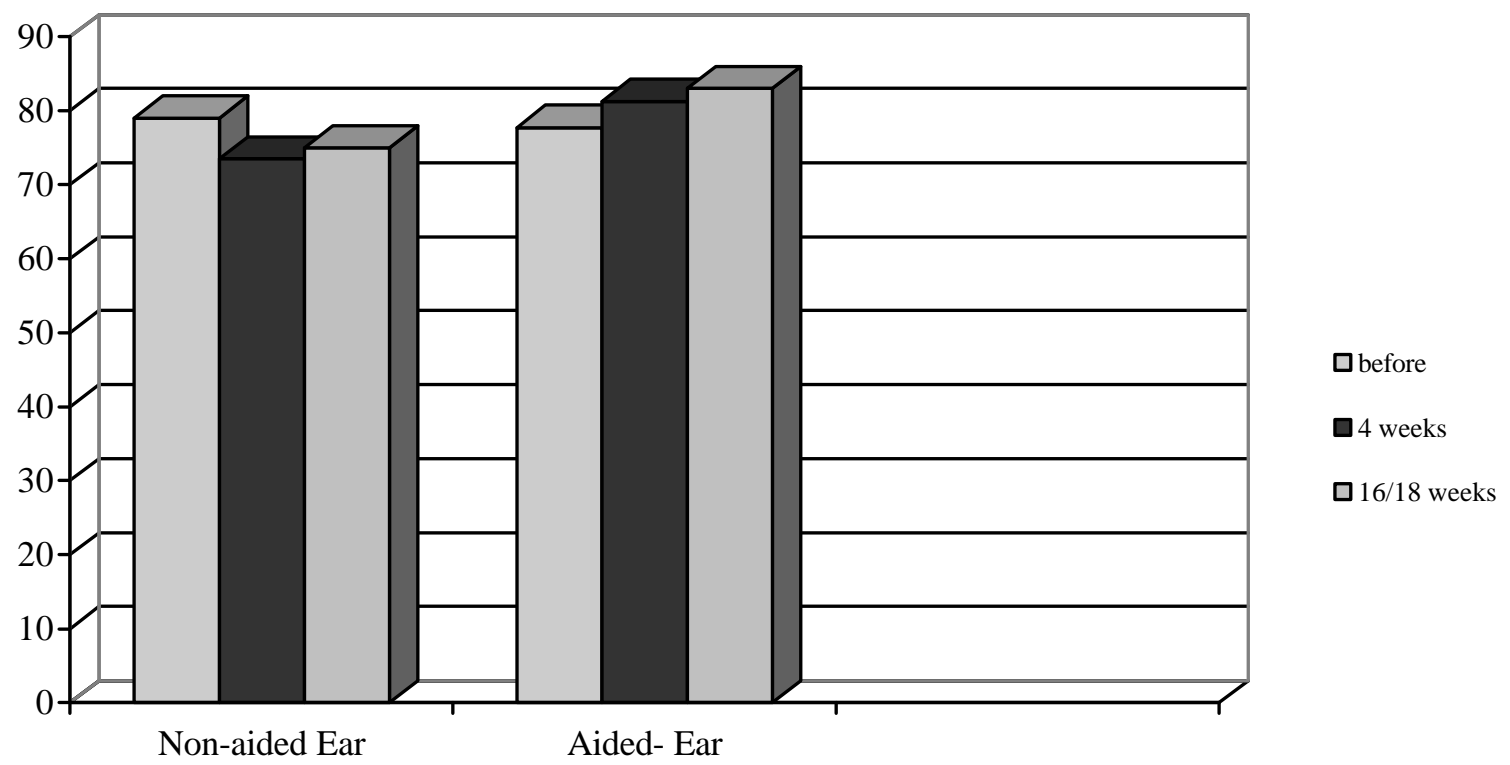


GRAPH 7 - Percentage Values Mean of Speech Discrimination scores from eight individuals with binaural amplification.

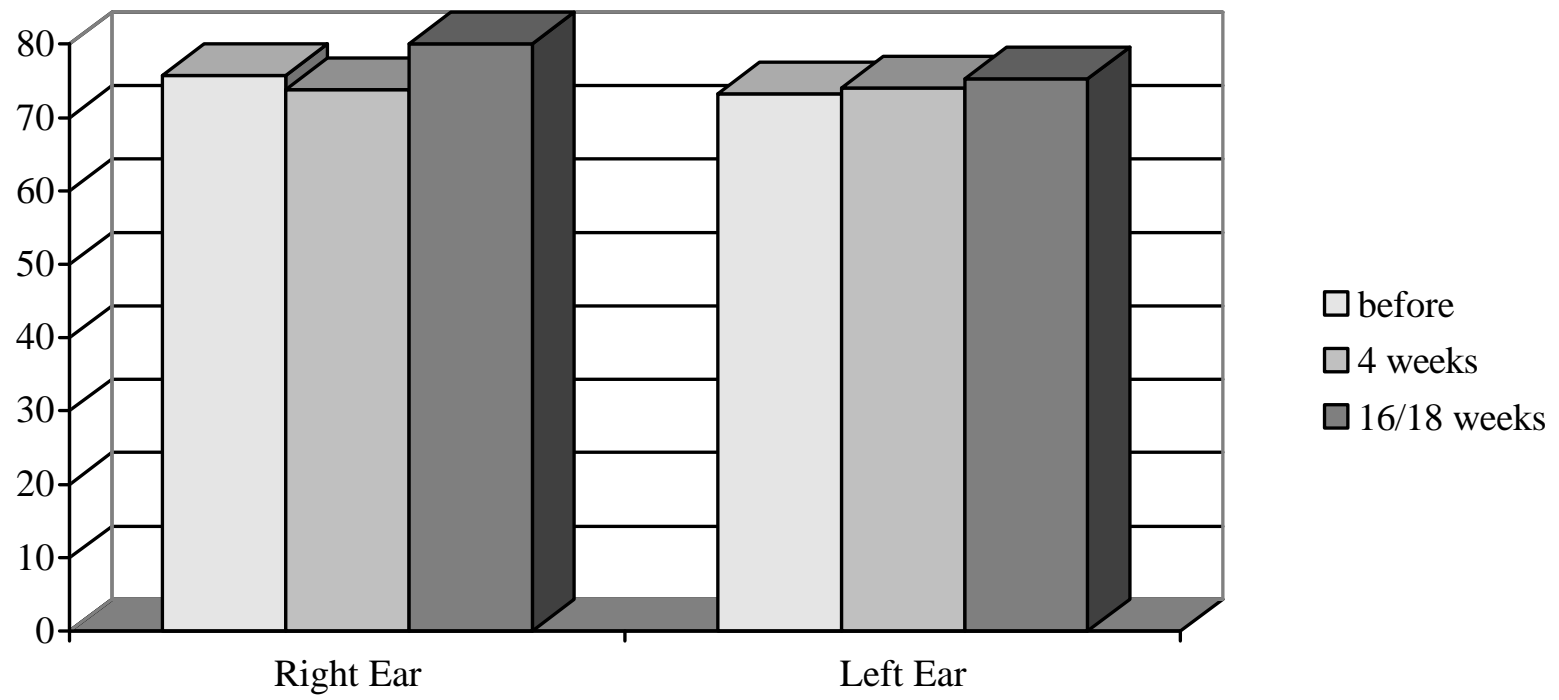

\section{Discussion}

\section{Part 1}

\section{Study of Auditory Benefit}

Subsequent to the hearing aids fitting process, patients were assessed through free- field audiometry to evaluate the H.A. performance. From the statistical analysis of t- test, was observed that there was a significant statistical difference in the conditions without and with hearing aids at all frequencies (Graph 1), demonstrating that occurred a modification of acoustical information available to participants, comparing to the previous condition. This result shows clearly the occurrence of short-term auditory benefit with the use of amplification.

In the literature, it was confirmed that several authors ratify that acclimatization only can occur due to a induced plasticity through the reintroduction of auditory acoustical stimulus, as the same way that the effects of auditory deprivation can result from plasticity associated to unbalancing quantity of sound waves entering both ears. Therefore, the objective of hearing aids usage or cochlear implant would be to induce through the reintroduction of stimulation of the plasticity mechanisms that optimize the auditory performance throughout a modification in the acoustical information available to the individual (Willot, 1996; Palmer, 1999; Tremblay, 2003).

In the subjective analysis of H.H.I.A. /E.-S., the t-test indicated through the comparation of phases before and after 4 weeks, and 16/18 weeks, a statistical difference among the average of two scales and total scale were significant evidently. After the use of amplification for 4 weeks, the majority of individuals presented a significant reduction in the self- perception of hearing handicap, decreasing the social and emotional outcomes of hearing impairment.

However, when was performed the analysis among the results obtained after four weeks with the results after $16 / 18$ weeks of hearing aids usage (Graph 2), there was not a significant changing in the average answer between the two phases. Therefore, as there was not a reduction of selfperception of hearing handicap after 16/18 weeks of use of hearing aids, it can be affirmed that an increase in the benefit was not observed.

In this current study could be observed a significant decrease of self-perception of hearing handicap after four weeks and not after 16/18 weeks of amplification usage. This result is analogous to other studies (Mulrow et. al, 1992; Humes et al., 2002; Dan e Iorio, 2004), in which demonstrated that the majority of first-time hearing aids users 
obtain a significant statistical decrease of selfperception of hearing handicap, and a significant social and emotional benefit, reflected by a decrease in the H.H.I.A./E.-S. Inventory scores, after a shortperiod of amplification usage (four to six weeks).

However, we have realized that even the reduction in the hearing handicap happened after four and 16/18 weeks, the highest decrease was observed after four weeks and after 16/18 weeks, in which there was a slight increase in the scores obtained in the two scales.

This result is similar to Weisntein findings (1997) who suggested that the high reduction of hearing handicap after a short-period (four weeks), could be justified by an initial aphorism and enthusiasm of the patient correspondent to positive expectations of hearing aids usage. We could observe through the patients follow-up along 16/ 18 weeks that after a long-period of use of hearing aids, it seems happening a decrease of the initial aphorism, and at this moment, they get to express themselves accurately and concisely.

The statistical analysis of A.P.H.A.B., the t-test indicated that, comparing phase before to 4 weeks and $16 / 18$ weeks, the difference among the mean values from the four scales was statistically significant (Graph 3). After four weeks and 16/18 weeks of amplification, it was observed that in the scales EC, RV and BN, the majority of individuals presented a significant increase in the benefit with hearing aids, meaning a less difficult at different communication environments. These findings are similar to a study performed in São Paulo, which was observed that hearing difficulties after hearing aids fitting process were statistically smaller after two months and six months at the same subscales: EC, RV and BN (Bucuvic e Iório, 2004).

The analysis of the scale Aversiveness (AV) showed an average increase, indicating a significant reduction of the benefit with hearing aids. After four weeks and 16/18 weeks of hearing aid usage, the participants experienced an increase at sound aversiveness. After four weeks and 16/18 weeks of hearing aids usage, it was observed a decrease at sound aversiveness, which could be explained by the increase of acoustical signals audibility after amplification. The Graph 4 presented mean values with negative scores at scale AV when comparing the benefit after four week $(-28,31 \%)$ and after $16 / 18$ weeks $(-21,00 \%)$, reflecting a worse performance of hearing aids usage over time. The other studies found in the literature, like the ones from Cox and Alexander (1995) and Almeida (1998) confirm the current study findings as well.
However, when the analysis was performed among the results obtained after four weeks of hearing aids usage and 16/18 weeks, there was not significant changing in the average answer among the scales EC, RV and BN. Therefore, it was not observed a significant increase of the benefit of hearing aids usage over time. Nonetheless, in the analysis of AV was detected a significant difference at the average answer after four weeks $(56,44 \%)$ and $16 / 18$ weeks $(48,63 \%)$. For that reason, in this analysis, there was a reduction of the mean values, indicating a decrease at sound aversiveness.

The last comparison was made among the benefit with the use of hearing aids obtained from the application of A.P.H.A.B. after four weeks and 16/18 weeks (Graph. 4). Only in the scale AV, the comparison after the four weeks and 16/18 weeks, had a difference statistical significant in the reduction of aversion to sounds, indicating that the individuals had an acclimatization to amplified sounds, and the sounds that were considered as uncomfortable before, after16/18 weeks of hearing aids usage, they had become more comfortable.

These findings are similar to the ones found by Byrne and Dirks (1996), who postulated the changing evidences of intense sound tolerance or amplification level preferred, after new auditory experiences. These authors in their studies, suggested that lower tolerance level can be increased with auditory stimulation, affirmative that justifies the success obtained with tinnitus masking to hyperacusis treatment. Generally, the decreasing in the AV over time hearing aids usage indicated that the acclimatization phenomenon could have influenced the current study result.

Clinically, this study emphasized the importance to consider the acclimatization effects and the auditory deprivation in the process of hearing aids fitting and its evolving.

In order to know that the obtained formal results of the benefit with hearing aids are correspondent to the wearer subject opinion, it is fundamental to perform an evaluation combined of objective and subjective measures of the benefit with hearing aids (Cox, 2003).

A study performed by Gatehouse et al. (2003) demonstrated that the benefits associated to other systems of acoustic signal process were influenced by audiometry variables, and by psychoacoustic abilities, listener characteristics (motivation, expectative, and personality), and as well the acoustical environment in which the listener was immersed. Consequently, the results of our study confirm the needs to perform measurements that 
provide a complete assessment of the benefit with hearing aids usage.

\section{Part 2}

Study of acclimatization phenomenon

Comparing the word discrimination scores of 24 aided-ears at two different moments, before and four week after of hearing aids usage, we have not found a significant statiscal difference among the mean of $5 \%$. As the same, we have not found a significant statistical difference among mean values from phase before and 16/18 weeks and 4 weeks and 16/18 weeks.

However there has not been a significant statistical difference among word discrimination scores, we can observe an increase in this speech discrimination over time wearing hearing aids, indicating an improvement scores (Graph 5). This improvement can be related to an occurrence of neuroplasticity. According to Musiek (2002), some auditory abilities related to cerebral function can be improved with auditory training. This training can influence auditory functions because the brain has plasticity ability.

In this study, the speech discrimination scores data of 8 individuals who had monaural fitting were related and compared. First, the results of the nonaided ear not at the three moments of the study had been compared. The same comparison was carried through with the results of the SD gotten in the aided ear. Finally, the results of the SD of the eight non-aided ears (group has controlled) had been compared with the results gotten in the eight aided ears (experimental group). In none of the mentioned comparisons above was found a significant statistical difference among the mean values with a level of significance of $5 \%$.

The comparisons between the speech discrimination (SD) of the experimental group (aided ear) with the SD of the control group (nonaided ear) had been carried through to observe a possible improvement in the performance of speech recognition over time after wearing hearing aids. Despite the results of the statistical analyses not having been significant, it was possible to observe in Graph 6 that the average of the SD of the non-aided ear decreased over time, and the other ear when compared to the phase before fitting process, the averages of the SD of the aided ears had presented an improvement with the use of the amplification over time.
Although there have not been observed a significant statistical difference, our results had been suggestive of the existence of the acclimatization effect (aided ears) and sensorial privation (non- aided ears) that occurred over time with wearing monaural hearing aids and had evidenced the interference of these effect in the ability of speech recognition of the monaural hearing aids users. Over time, occurred an improvement in the performance of the abilities of speech recognition in the aided ears and a worsening in the performance of the abilities of speech recognition in the non- aided ears; however these results had not been significant.

For this reason, we agree to Boèchat (2002) who suggested that monaural hearing aids creates a interaural asymmetry that results in a decrease in the ability of speech recognition in the non-aided ear. In contrast, the aided ear improves the ability performance of speech recognition with an increase of the proportional audibility of the hearing aids.

In our study, we do not observe the occurrence of the phenomenon of the acclimatization, although we perceived an improvement of the averages of the SD of aided ears that had received amplification over time with hearing aids usage. Other authors (Humes and Wilson, 2003; Munro, and Lutman, 2003; Munro, and Lutman, 2004; Philibert et al, 2005) had carried through studies where they had observed small evidences of the occurrence of the acclimatization phenomenon.

It is worth to stand out that the considered sample in this analysis was small and that would be necessary to observe a higher number of individuals.

Once more, the test of Wilcoxon Signed Ranks was used to carry through the statistic analysis of the SD of the eight individuals that had received binaural amplification. This test was used to compare the SD of the right ear with the SD of the left ear at different moments: previous the fitting process, after four weeks and after 16/18 weeks.

But in the comparison of the right ear with the left after 16/18 weeks, the difference was significant statically (Graphic 7). We can observe that at the previous moment to the one of the fitting process of the hearing aids, the average of the SD of the right ear was superior to the one of the left ear. Will be the ears that present a better SD before the fitting process of the hearing aids have greater possibilities to improve still more the speech recognition with stimulation over time?

These comparisons between the SD of the right ear with the SD of the left ear had been carried through to observe a possible improvement in the 
performance of the speech recognition after a period of time wearing hearing aids. Despite the average of the SD of the right ear presented a decrease after four weeks of amplification use, it was possible to observe in Graph 7 that the average of the SD of both ears at the other phases increased over time with the use of hearing aids.

Although our findings have not been significant, we agree to Boèchat (2002), who concluded that all and any process of evaluation or verification of the benefit with hearing aids must consider the acclimatization phenomenon.

In addition to literature studies (Arlinger, 2003), it was accurately observed, in the cases of monaural fitting, the improvement of the SD of aided ear and the worsening of the SD of the non-aided. These findings are in accordance with the study of diverse authors (Byrne and Dirks, 1996; Boèchat, 2002) that consider the occurrence of the acclimatization phenomenon of and the sensorial privation.

However Neuman (2005) affirmed that so far there is not a direct relation among the changes of the auditory performance and the central auditory system, however for the author, the available techniques of electrophysiological measurements currently can briefly become this possible to confirm or not this relation.

On the other hand, it is our responsibility to question if the acclimatization effect is really perceived by the hearing aid users, and if they feel benefited with this phenomenon. In order to perform this, we will need to follow our patients for a longer period of time and to evaluate the benefit by means of subjective measures and electrophysiological measurements. It is necessary to also consider if the auditory training could assist them directly in the improvement of the speech recognition ability.

\section{Conclusion}

By means of the analysis of the results acquired in the present study we conclude that:

. have been observed a significant statiscal difference in the objective and subjective measures after the use of the hearing aids, indicating shortterm auditory benefit;

. with the use of amplification over time did not result a significant improvement of the benefit, suggesting that the benefit does not increase along time;

. there was an improvement of the average of the Speech Discrimination scores and the subjective measures of the benefit over time wearing hearing aids, however these differences had not been statistically significant. Therefore, it was not possible to verify the occurrence of the acclimatization phenomenon by means of the Speech Discrimination scores.

\section{References}

ALMEIDA, K. Avaliação objetiva e subjetiva do benefício de próteses auditivas em adultos. 1998. Tese (Doutorado em distúrbios da comunicação humana) - Departamento de Fonoaudiologia, Universidade Federal de São Paulo, São Paulo.

ARLINGER, S. Negative consequences of uncorrected hearing loss: a review. Int. J. Audiol., Linkoping (Sweden), v. 42, suppl. 2, p. 17-20, jul. 2003.

ARLINGER, S.; GATEHOUSE, S.; BENTLER, R. A.; BYRNE, D.; COX, R. M.; DIRKS, D.; HUMES, L.; NEUMAN, A.; PONTON, C.; ROBINSON, K.; SILMAN, S.; SUMMERFIELD, A. Q.; TURNER, C. W.; TYLER, R. S.; WILLOT, J. F. Report of the Eriksholm workshop on auditory deprivation and acclimatization. Ear Hear., Glasgow (UK), v. 17, suppl. 3, p. 87-90, jun. 1996.

BOÈCHAT, E. M. Plasticidade do sistema auditivo quanto à sensibilidade auditiva para tons puros e respostas para a fala na deficiência auditiva neurossensorial. 2002. $175 \mathrm{f}$. Tese (Doutorado em fisiopatologia experimental) Universidade Federal de São Paulo, São Paulo.
BRASIL. MINISTÉRIO DA SAÚDE. Estatuto do idoso. Lei n. 10741 de 1 de outubro de 2003, título 1, art. 1 . Brasília. Disponível em: <http://portal.saude.gov.br/portal/ arquivos/pdf/ estatuto_do_idoso.pdf >. Acesso em: 12 maio 2005.

BRASIL. Resolução MS/CNS/CNEP n. 196/96, de 10 de outubro de 1996. Aprova diretrizes e normas regulamentadores de pesquisa envolvendo seres humanos. Brasília (DF). Disponível em: <http:// conselho.saude.gov.br/docs/resoluções/reso196.doc>. Acesso em: 12 maio 2005.

BUCUVIC, E. C.; IÓRIO, M. C. Benefício e dificuldades auditivas: um estudo em novos usuários de prótese auditiva após dois e seis meses de uso. Fono Atual, São Paulo, v. 29, n. 7, p. 19-29, jul.-set. 2004.

BYRNE, D.; DIRKS, D. Effects of acclimatization and deprivation on non-speech auditory habilities. Ear Hear., v. 17, suppl. 3, p. 2937-2977, jun. 1996. 
COX, R. Assessment of subjective outcome of hearing aid fitting: getting the client's point of view. Int. J. Audiol., v. 42, suppl. 1, p. S90-S96, jul. 2003.

COX, R. M.; ALEXANDER, G. C. The abbreviated profile of hearing aid benefit. Ear Hear., v. 16, n. 2, p. 176-183, apr. 1995.

DAN, I. B.; IÓRIO, M. C. Dificuldade e desvantagem auditivas: estudo em idosos na adaptação de próteses auditivas. Fono Atual, São Paulo, v. 29, n. 7, p. 50-59, jul.-set. 2004.

DAVIS, H.; SILVERMAN, S. R. Auditory test hearing aids. In: DAVIS, H.; SILVERMAN, S. R. Hearing and deafness. New York: Holt Rinehart and Winston, 1970.

DILLON, H.; NAL NL1: a new procedure for fitting nonlinear hearing aids. J. Speech Hear. Disord., v. 52, n. 4, p. 10-16, apr. 1999.

GATEHOUSE, S.; GRAHAM, N.; CLAUS, E. Benefits from hearing aids in relation to the interaction between the users and the environment. Int. J. Audiol., v. 42, suppl. 1, p. S77-S96, jul. 2003.

HUMES, L.; WILSON, D. L.; BARLOW, N. N.; GARNER, C. Changes in hearing-aid benefit following 1 or 2 years of hearing-aid use by older adults. J. Speech Lang Hear Res, v. 45, n. 4, p. 772-784, aug. 2002.

HUMES, L.; WILSON, D. An examination of changes in hearing aid performance and benefit in the elderly over a 3-year period of hearing-aid use. J Speech Lang. Hear. Res., v. 46, n. 1, p. 137-145, feb. 2003.

INTERNATIONAL STANDARDS ORGANIZATION. Acoustics-audiometric test methods, I: basic pure tone air and bone conduction threshold audiometry. ISO 8253-1, 1989.

MUlROW, C.; TUlEY, M.; AGUILAR, C. Sustained benefits of hearing aids. J. Speech Hear. Res., v. 35, p. 1402-1405, dec. 1992.

MUNRO, K.; LUTMAN, M. The effect of speech presentation level on measurement of auditory acclimatization to amplified speech. J. Acoust. Soc. Am., v. 114 , n. 1 , p. $484-495$, jul. 2003

MUNRO, K.; LUTMAN, M. Self-reported outcome in new hearing aid users over a 24 -week post-fitting period. Int. J. Audiol., v. 43, n. 10, p. 555-562, nov.-dec. 2004.

MUSIEK, F. Auditory plasticity: what is it, and why do clinicians need to know? J. Speech Hear. Dis., v. 55, n. 4, p. 70 , apr. 2002.
NEUMAN, A. Central auditory system plasticity and aural rehabilitation of adults. J. Rehabil. Res. Dev., v. 42, suppl. 2, p. 169-185, jul.-aug. 2005.

PALMER, C. V. Deprivation and acclimatization in the human auditory system: do they happen? Do they matter? J. Speech Hear. Dis., v. 52, n. 11, p. 23-24, nov. 1999.

PEN, M. G.; MANGABEIRA-ALBERNAZ, P. L. Desenvolvimento de teste de logoaudiometria: discriminação vocal. In: CONGRESSO PAN AMERICANO DE OTORRINOLARINGOLOGIA Y BRONCOESOFASOLOGIA, 2., 1973, Lima. Anales, Lima (Peru): [s.n.], 1973. v. 2, p. 223-226.

PHILIBERT, B.; COLLET, L.; VESSON, J. F.; VEUILLET, E. The auditory acclimatization effect in sensorineural hearing-impaired listeners: evidence for functional plasticity. Hear. Res., v. 205, n. 1 e n. 2, p. 131-142, jul. 2005.

RUSSO, I.; LOPES, L.; BRUNETTO-BORGIANNI, L.; BRASIL, L. Logoaudiometria. In: SANTOS, T. M. M.; RUSSO, I. C. P. A prática da audiologia clínica. 5. ed. São Paulo: Cortez, 2005. p. 135-154.

SILMAN, S.; GELFAND, S. A.; SILVERMAN, C. A. Late onset auditory deprivation: effects of monoaural versus binaural hearing aids. J. Acoust. Soc. Am., v. 76, n. 5, p. 1357-1362, nov. 1984.

TREMBLAY, K. Central auditory plasticity: implications for auditory rehabilitation. J. Speech Hear. Disord., v. 56 , n. 1, p. 10-15, jan. 2003.

VENTRY, I. M.; WEINSTEIN, B. E. The hearing handicap inventory for the elderly: a new tool. Ear Hear., v. 3, n. 3, p. 128-134, may-jun. 1982.

WEINSTEIN, B. Treatment efficacy: hearing aids in the management of hearing loss in adults. J. Speech Hear. Res., v. 39, n. 5, p. S37-S45, oct. 1996.

WEINSTEIN, B. Outcome measures in the hearing aid fitting-selection process. Trends Amplif., v. 2, n. 4, p. 117-137, 1997.

WIESELBERG, M. B. A auto-avaliação do handicap em idosos portadores de deficiência auditiva: o uso do HHIE. 1997. Tese (Mestrado em distúrbios da comunicação humana) - Pontifícia Universidade Católica, São Paulo.

WILLOT, J. F. Physiological plasticity in the auditory system and its possible relevance to hearing aid use, deprivation effects and acclimatization. Ear Hear., v. 17, p. 665-775, jun. 1996 